\title{
Implementation of Data Mining Technology in Bonded Warehouse Inbound and Outbound Goods Trade
}

\author{
Yanan Song, Macau University of Science and Technology, China \\ Xiaolong Hua, Inner Mongolia University of Finance and Economics, China
}

\begin{abstract}
For taxed goods, freight is generally determined by multiplying the allocated freight for each $\mathrm{kg}$ and outgoing weight based on the outgoing order number on the outgoing bill. Considering that conventional logistics is insufficient to cope with the rapid response of e-commerce orders to logistics requirements, this work discussed the implementation of data mining technology in bonded warehouse inbound and outbound goods trade. Specifically, a bonded warehouse decision-making system with data warehouse, conceptual model, online analytical processing system, human-computer interaction module, and web data sharing platform was developed. The statistical query module can be used to perform statistics and queries on warehousing operations. After the optimization of the whole warehousing business process, it only takes 19.1 hours to get the actual freight, which is nearly one-third less than the time before optimization. This study could create a better environment for the development of China's processing trade.
\end{abstract}

\section{KEYWORDS}

Bonded Warehouse, Cost Settlement, Data Mining, Inbound and Outbound Goods, Statistical Query

\section{INTRODUCTION}

Since the 21st century, global economic integration has become the trend of world economic development. With the international flow of production factors and the large-scale development of international trade on a global scale, the economies of various countries are further dependent and influenced by each other. In the environment of fierce corporate competition and global economic integration, undifferentiated competition models such as large-scale product production and traditional marketing strategies can no longer meet the needs of the market. It is necessary to meet the needs of customers and make correct judgments on market trends in a timely manner. As a new growth point in the development of modern logistics, bonded logistics has received increasingly attention from the industry, and has become an interesting theme in regional economic development. Also, it plays an important role in implementing the overall strategy of national regional development. Internationally, the customs' bonded supervision is positioned as a preferential policy to promote the economy, and the relevant system is known as the economic supervision system. Bonded logistics supervision directly reflects the promoting effect of the customs on the economy. Formulating differentiated marketing 
strategies based on market segments has become the only way for enterprise development. Supply chain management has gradually become an important part of enterprise competitiveness. Enterprises are paying increasing attention to supply chain and logistics management. In order to seek resources in the world, make full use of international logistics networks and facilities, reduce logistics costs of enterprises, and improve the comprehensive competitiveness of enterprises, the establishment of a global logistics center or goods distribution center has become an inevitable choice for multinational production enterprises.

The optimized import filing and tax payment process are due to the operation of the allocation project. The efficiency of customs clearance and customs clearance of goods that can be distributed and shipped has been greatly improved. According to the ECRS analysis method, the original unnecessary procedures are canceled, and the necessary procedures are merged, rearranged and simplified. The import and export department of the company also began to prepare the information of the goods involved in the inspection after the goods were actually put into the warehouse, and after the forwarding forecast was received in advance and the import and export department began to enter the data in the MISIE system, which also sped up the process. It proved the efficiency of customs clearance of goods involved in inspection. Through the system simulation of the planning and design scheme, this study can dynamically observe the operation of the whole warehousing and logistics links, facilities and equipment in real time, and find the congestion link of the logistics operation system. It can provide theoretical support for the actual warehouse logistics planning and design. Bonded logistics is a significant part of the supply chain operation in multinational companies. It runs through the entire supply chain in international trading companies. Affecting the supply chain level of enterprises with bonded functions, high-level bonded logistics is also one of the important competitiveness of international trading enterprises. With the continuous expansion of international logistics business and the continuous update and improvement of international logistics operation mode, it also puts forward higher requirements for the functions of bonded logistics while promoting the development of bonded logistics. Combined with the logistics simulation system, the operation result analysis has important theoretical significance for improving the utilization rate of warehousing space and improving the efficiency of warehousing logistics. The application of system engineering theory in warehousing logistics has been expanded. With the integration of the global economy, the development of international trade and the intensification of competition among enterprises, the collaboration among enterprises with regard to products, technology, and finance is constantly deepening. All enterprises regard the development of supply chain as an important strategic goal for their long-term development. The service level has also become the main way for companies to provide differentiated services. Logistics is an indispensable part of the supply chain, and its service level is a essential indicator to measure an enterprise.

As a warehousing enterprise in the bonded area, the company's import and export business is the core of the company's operation. After more than ten years of development, the company's business volume has continuously increased, and the amount of imported and exported goods has also doubled. These all pose challenges to the current export process. Accordingly, this study optimized the company's import and export process. The background of inbound and outbound goods trade in bonded warehouses was explained, and the meaning of data mining technology in bonded warehouses was described in detail. The experimental part was an introduction to data mining and inbound and outbound goods trade in bonded warehouses, and it also coped with data mining and the trade of inbound and outbound goods in bonded warehouses and the application of data mining technology to the trade in inbound and outbound goods in bonded warehouses. The discussion section optimized the distribution of inspection items in logistics operations. 


\section{RELATED WORK}

With the liberalization of international trade and investment, export processing zones (EPZ) are becoming increasingly important. Yucer A believes that EPZ is a key player in deepening the global value chain $(\mathrm{GVC})$. He aims to improve the knowledge in this field by analyzing the trade performance of EPZ countries at a macro level, focusing on the externalities and distorting costs of EPZ. He established a raw database of export processing zones, in which he defined it as processing zones that enjoyed import tariff preferences. He stated that export processing zones only increase trade by mitigating the negative effects of protection. As importers of parts and raw materials, they have increased exports from other parts of the world. Although his research has confirmed the contribution of EPZ to GVC, it cannot be proved that the results are robust against changes, errors and deviations in model specifications due to data collection issues and sample composition (Yüce, 2017). Yan X S constructed a "universe" containing more than 18,000 fundamental signals from financial statements, and used guided methods to evaluate the impact of data mining on fundamental anomalies. He found that many fundamental signals were important predictors of cross-sectional stock returns, even when data mining was taken into account. This predictive ability is more pronounced after periods of high sentiment and in stocks with greater arbitrage restrictions. In his study, the fundamental anomalies and the new anomalies found in this study can not be attributed to random opportunities, and they can be better explained by mispricing. Although his method is universal, the research process is not very comprehensive (Yan., 2017). To Pc Uolu A believes that all countries need to increase production and income levels in order to increase the speed of social and economic progress and development. One of the most important tools used by countries to increase production and national income is foreign trade. In recent years, Turkey has been trying to improve its foreign trade with other countries. Through the input-output model, he determined the foreign trade relations, key industries and import dependence analysis with Turkey and mist countries. Within the scope of the analysis, the Leontief inverse matrix, key industries and import inverse matrix were calculated for all countries with WIOD data in 2014. Although his research determined that the products produced by computer, electronics and optics are the key, the amount of data in the research process is relatively small (To Pc Uolu, 2020). Dar Q $\mathrm{F}$ believes that the recent growth of Korean products in the international market is a benchmark for developed and developing countries. From the development index, the role of international trade in the development of the national economy is indeed crucial. However, the visualization of a country's international trade profile is a prerequisite for government decision-makers and foreign trade forecast guidance. He used data visualization technology to visualize Korea's import and export product space and trading partners. Economic complexity index (ECI) and revealed comparative advantage (RCA) were used to identify the diversification of Korea's international trade, while the time series method was used to predict economic and foreign trade variables. In his research, Korea's ECI has increased significantly compared with China, Hong Kong and other developed countries in the world, while the research process lacks innovation (Dar., 2020). The operation and management of an enterprise is inseparable from the process, and the process management has been widely used by the enterprise. Process optimization is an indispensable part of enterprise process management. The process optimization theory has been maturely used in the optimization process of enterprises and institutions, and its research results are also quite rich. Many rich theoretical foundations and diversified operating tools have been formed in practical work.

\section{RESEARCH METHOD}

\section{Bonded Warehousing}

Apart from the storage and logistics functions of general warehousing, bonded warehousing also combines customs supervision and bonded systems. Its main functions and effects can be summarized as follows (Buczak., 2015): 


\section{Temporary Tax Exemption for Imported Goods}

It lies in the cooperation of freight forwarders. As the company's import and export business volume is continuously increasing, freight forwarders can also get more preferential transportation prices when negotiating. Simultaneously, several large multinational companies around the world formed an alliance, negotiated with freight forwarders, and reached an internal GSA freight price, which was much lower than the price of companies outside the alliance. After the imported goods arrive at the port, they can be sent to the bonded warehouse of the enterprise by declaration to the customs. It is the most basic function of bonded warehousing to suspend the import tariff and value-added tax of imported goods, and it is also the most profitable function of bonded warehousing enterprises. This function can help enterprises improve the speed and efficiency of customs clearance, thereby shortening the inventory cycle of import and export products, and thus shortening the delivery time of international trade goods. Imported goods can also be stored in bonded warehouses in a bonded form, which reduces the cost of inventory products for enterprises. The area of warehousing temporary storage area is (Helma, 2004; Wang, 2019):

$$
S=K \times Q \times \frac{v_{x}-V_{z}}{h \times t} S_{T}
$$

As the company's core department, it should work well with other business departments of the company to achieve the company's long-term strategic goals while doing its own job. Besides, the import and export business process based on changes in the internal and external environment should be optimized. $S_{T}$ refers to the area of temporary storage area. $K$ is the unbalanced fluctuation coefficient. The area of temporary storage area for bonded warehouse is (Chaurasia., 2017):

$$
S_{L}=K \times Q \times \frac{v-v_{s}}{h_{L} \times t_{L}} \times S_{T}
$$

$S_{L}$ refers to the area of the warehousing tally area. $v$ refers to the loading speed of goods into the storage area. The area of warehousing storage area is (Xu, 2014):

$$
S_{C}=\frac{Q_{C} \times T \times K}{t \times q \times f}
$$

$T$ is the average storage days of goods. The area of warehousing inbound sorting area is $(\mathrm{Fu}, 2020)$ :

$$
S_{F}=\frac{Q_{F} \times T_{J} \times K}{t_{F} \times q_{F}}
$$

$T_{J}$ refers to the time to complete a sorting operation. The area of packaging area is (Atimu., 2020):

$$
S_{F H}=\frac{Q_{F H} \times T_{F H} \times K}{t_{\mathrm{FH}} \times q_{F H}}
$$

The area of the return and recovery area is: 
$S_{T}=S_{R}+S_{T C}=\frac{Q+Q_{T C}}{Q \times J}$

$Q_{T C}$ is a part of the returned goods at the time of warehousing (Fu, 2020).

\section{International Cargo Distribution and Distribution}

Bonded warehousing plays an important undertaking link in international bonded logistics, connecting with important circulation links such as production, distribution and transportation of bonded logistics. Bonded warehousing enterprises can use the preferential conditions provided by the customs to transit and distribute goods in international trade. The goods purchased from abroad can be put into bonded warehouse for filing. Moreover, the goods can be sorted, simply repackaged, repackaged, marked, assembled, etc., and then re-distributed to domestic and foreign customers, providing value-added services to the goods. Some multinational companies set up their international distribution centers in special customs supervision areas, and re-distribute temporarily imported goods according to the special requirements of domestic and foreign customers. On the one hand, enterprises can make more profits by reducing logistics costs and improving the international competitiveness of enterprises. On the other hand, it is convenient for enterprises to offer services and shorten the delivery of goods, which meets customers' needs and further promotes the development of international trade (Sikos. 2020). International cargo distribution and distribution are shown in Figure 1.

Figure 1. International cargo distribution and distribution

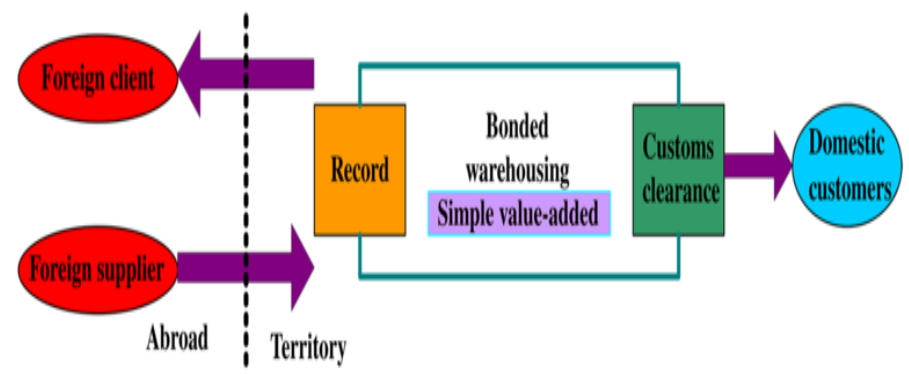

Figure 2. Collecting and shipping

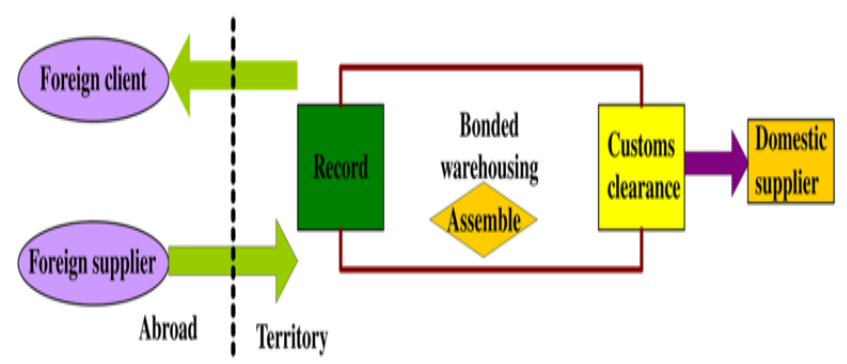




\section{Collecting and Shipping and International Transit}

Enterprises may purchase from domestic and foreign suppliers respectively, and domestic enterprises shall go through export declaration procedures. Foreign goods shall go through the entry filing procedures and be stored in bonded warehouse under the condition of tax exemption. After receiving clear instructions from foreign customers, the goods purchased from domestic and foreign suppliers will be repackaged and filed for departure according to their requirements (Yensu.,2019). The collecting and shipping are shown in Figure 2.

\section{Diversified Forms of Trade}

Under the bonded supervision of the customs, bonded warehousing can carry out various and complex forms of trade, such as customs transfer, transit, in-area warehouse transfer, free form and other special trade. Customs transfer is to transfer bonded goods in two different customs special supervision areas with customs supervision vehicles under customs supervision. If both enterprises are registered in the special supervision area of the customs, they can directly apply for customs transfer (ShokoohiYekta, 2017). The transition process is shown in Figure 3.

\section{Figure 3. Customs transfer process}

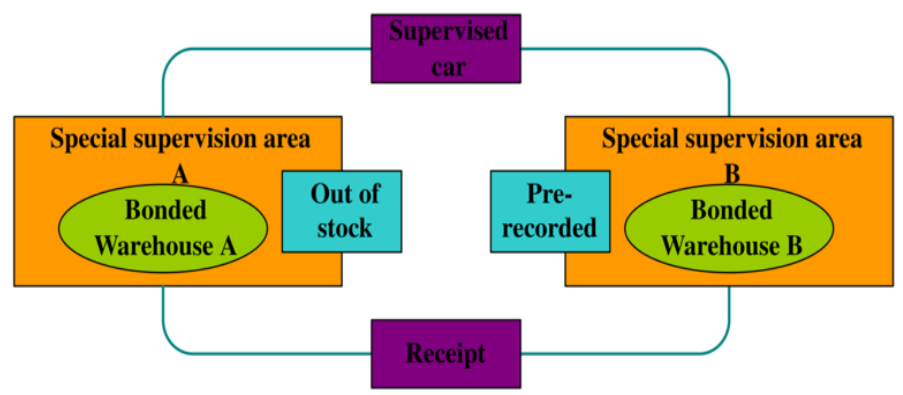

Transit trade refers to international trade in the import and export of goods sold through a third country to achieve, rather than directly between the country of origin and the country of final use. It is aimed at a third country. After the import and export goods are recorded in bonded warehouse in a third country, they are not processed but stored and shipped directly to the final consumer country. This type of trade is also tax-free and certificate-free for third-country companies, and is not subject to corporate quotas. At the same time, it can also avoid trade barriers in some countries, and even enjoy the preferential tax rate of the destination country and reduce the tariffs of import companies. Therefore, this trade situation is also respected by many companies. Transit trade truly realized the free

Figure 4. Process of importing and exporting goods

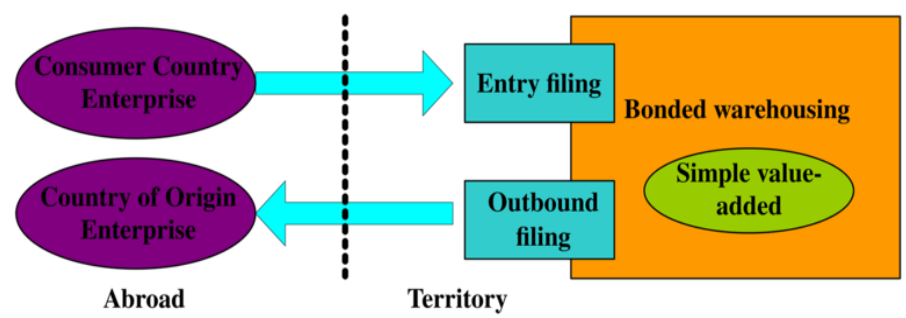


trade of international goods and promoted the further development of international trade (RamírezGallego, 2017). The process of importing and exporting goods is shown in Figure 4.

Warehouse transfer trade means that two bonded warehouse companies are registered in the same special customs supervision area. If there is trade between the two enterprises, they can be transported and paid freely after applying to the local customs for warehouse transfer. This kind of trade mode is quite convenient for the property rights transfer of bonded goods. Due to the same supervision area, there is no complicated customs clearance procedure for the transfer of goods, and there is no need to use customs supervision vehicles. For enterprises, it can greatly reduce the inventory turnover rate of goods, shorten the delivery time of goods, reduce transportation and inventory costs, and recover funds as soon as possible (Emoto, 2017).

\section{The Overall Framework of the Warehousing Decision-Making System}

\section{Overall Design Plan}

Design plan: after studying this problem from many aspects and investigating the reality, a feasible system solution was put forward. A bonded warehouse decision-making system with data warehouse, conceptual model, online analytical processing system, human-computer interaction module and web data sharing platform was designed (Hong, 2018).

In this program, the data warehouse mainly performs data storage and organization, and the data analysis stage is completed in OLAP. Data mining is performed according to the actual business, and the expected program is customized. The WEB server publishes and shares the circulation commodity data. Each module cooperates together and takes different decisions based on the actual needs of users to achieve preset goals (Moustakas., 2017). The architecture of the bonded warehouse decision support system is shown in Figure 5.

Figure 5. The architecture of the bonded warehouse decision support system

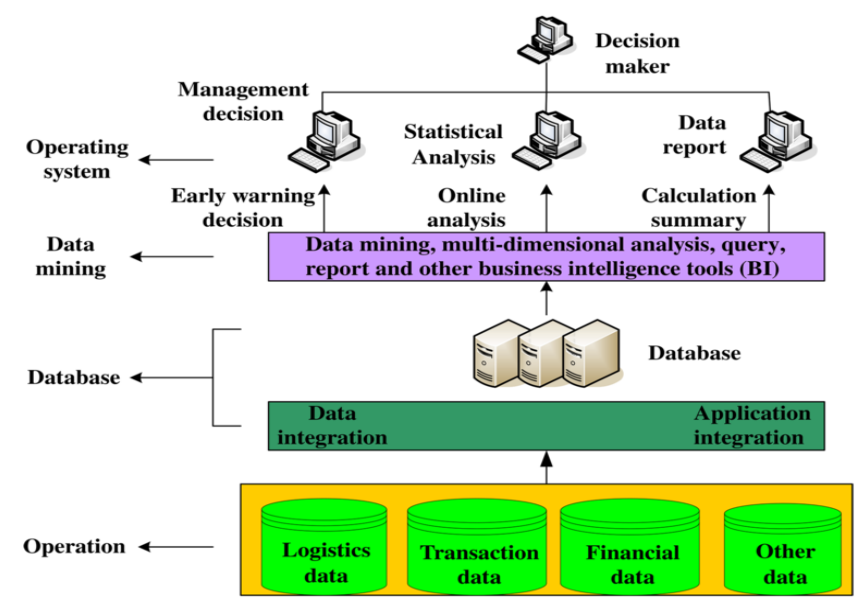

The bonded warehouse decision-making system can be divided into four levels: source data storage layer, data storage layer and management layer, system function module layer and humancomputer interaction system. This is divided according to the system structure. The second layer is data storage and management. The data comes from the daily operation of the first layer. The third layer is the system function module layer, which cooperates with the second layer to complete the whole decision-making process. This layer includes model base and decision file base, which can help to obtain decision information. Also, it mainly uses mining tools to build model and complete the 
work of building scheme. The fourth layer is the human-computer interaction system, which mainly completes the docking between users and the system. This layer offers decision-making solutions to decision-makers in form of reports, OLAP, real-time query and data mining (Constantine., 2017).

\section{The Network Topology of the Bonded Warehouse Decision-Making System}

In order to adapt to the development of the times, the bonded warehouse decision-making system also needs network support. In the network construction of logistics enterprises, there is no need to worry about the impact of the newly built network on its own network. As they can share a network environment, the network topology of the entire system is shown in Figure 6.

Figure 6. The network topology of the entire system

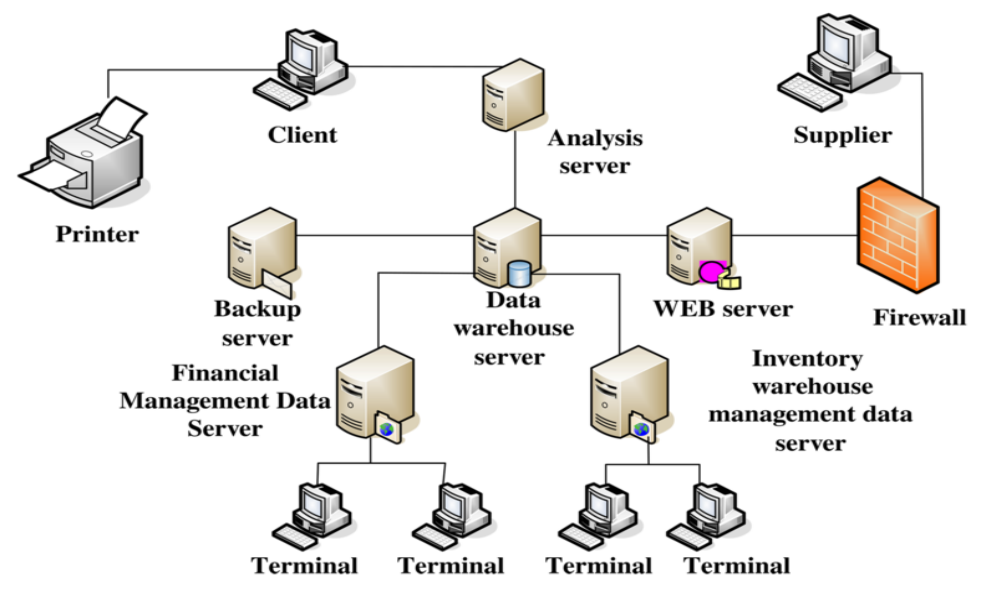

The "bottom-up" design scheme is easy to understand and commonly used, and thus it is adopted by this system. The first step is to establish an analysis and processing environment and extract raw data from the transaction database system. Before the data in the daily transaction processing database flows into the data warehouse and multidimensional data set, a series of operations need to be carried out. It can flow into the system through the processing of filtering, conversion and extraction module. In order to ensure that the analysis environment and processing environment do not affect each other and separate from each other, the data warehouse uses its own independent relational database for later data processing. OLAP can be used for one-to-one topic analysis and multiple dimensional data processing. It adopts multiple angle and multiple analytical methods, and constructs the analysis oriented multidimensional data model by analyzing and comparing the multidimensional data sets. OLAP starts from the integrated data in the data warehouse, and its analysis activities are driven by data, independent of method. It separates the analysis method from the data structure. Data mining is mainly carried out on automatic potential mining data, and the basis of these mining is a large amount of data. The sources of these data are mainly data warehouses and multidimensional databases. These potential patterns are the basis for making prediction automatically and providing decision makers with recommended decision schemes.

\section{Two Important Modules in the System}

a. Expense settlement module 
Currently, the cost settlement of warehousing enterprises in the bonded area is calculated by the warehouse managers, which is susceptible to cause errors. With the cost settlement module, the labor cost is saved and the result is more accurate.

b. Statistical query module

The system can be used to perform statistics and query on warehousing operations. For the operation of the company's employees, it can make managers fully understand the use of resources and efficiency, and offer information for managers to make wise decisions. For customers, they can know their inventory at any time through independent query.

\section{Functions Completed by the System}

\section{a. Inventory strategy mining}

The storage number, storage quantity, unit price, storage period, ratio of inventory quantity and ratio of total value of goods in warehouse management were analyzed. Classified analysis method and other mining techniques are used to determine the inventory management measures for different goods and make reasonable inventory strategies.

\section{b. Warehousing operation mining}

The data involved in the warehousing practice of the warehousing module and the outbound module in the logistics warehousing management system were collected. The data processing platform was built, and the corresponding data mining algorithm was used to mine, thus forming some potential useful information that is insusceptible to be found and forming the decision support for the storage operation.

\section{c. Customer management mining}

From the customer information database in the logistics warehouse management system, the effective, unknown and easy to understand information was extracted. The decision tree algorithm was used to mine to maintain old customers and develop new customers.

\section{Construction of Data Warehouse}

\section{Visual Tools for Data Mining}

With the international flow of production factors and the large-scale development of international trade on a global scale, the economies of various countries are further dependent and influenced by each other. In the fierce competition of enterprise data mining and the global economic integration environment, large-scale product production and conventional marketing strategies and other undifferentiated competition models can no longer meet the needs of the market. Satisfying the needs of customers, making correct judgments on market trends in a timely manner, and formulating differentiated marketing strategies based on data mining market segments have become the only way for enterprise development.

The first layer is the data warehouse server, which mainly completes the cleaning, conversion and loading of the source data. It connects with the transactional relational database system operated by the enterprise. The second layer is OLAP server, which aims at the data platform of the data warehouse above. Through on-line analytical processing, the final customer's requirements are decomposed into 
multiple analysis actions to produce analysis results. The third layer is the front-end display tool, which is provided by data mining tools or implemented by user programming. It is often displayed to users in concise and clear forms such as data reports, charts, etc.

Supply chain management has gradually become a crucial part of the enterprises competitiveness, and enterprises are paying increasing attention to the management of supply chain and logistics. In order to seek resources worldwide, make full use of international logistics networks and facilities, reduce the enterprises logistics costs, and improve the enterprises overall competitiveness, the establishment of a global logistics center or cargo distribution center has become an inevitable choice for multinational production enterprises. Data mining tools are an indispensable and important part of the inventory decision-making system. The mined data may come from data warehouses, transaction databases, streaming media files or other data sources, and data mining products provide a common interface to access these data. The interface of data mining tools expands the channels for data mining tools to obtain data. Like OLAP, they also need to clean, transform and load the data when data mining tools extract data. Only in this way can the correctness of the mining data be guaranteed. For the system studied in this work, the data mining tool will extract data from the data warehouse, and mine the data in the data warehouse according to the decision tree algorithm. Moreover, the information offered by the front-end access tool of the data warehouse is the auxiliary information for the decision maker. The human-machine interface of the decision-making system provides a visual connection to realize the intuitive use of information. Concurrently, the information can be stored in the database table by programming, and then written into the visual window through the control call.

The allocation rate of activity cost drivers is the amount of activity cost per unit of activity cost drivers. The main calculation formula is (Triguero., 2017):

$$
R_{j}=\sum_{i=1}^{n} c_{i n} / A
$$

$c_{\text {in }}$ is the total cost of the operation. The formula for establishing labor productivity is (Lin., 2014):

$$
A=\frac{Q}{T_{z}+\sum T V+T V n}
$$

Among them:

$$
T=\frac{V(1+g)^{n-1}}{(1+i)^{n}}
$$

$A$ is labor productivity. $T$ is the labor cost of the nth year (Varley., 2017).

\section{Realizing the Key Technology of Inventory Storage Decision Support System}

Import and export business is the core of bonded warehousing company. The efficiency of customs clearance will affect the company's customer satisfaction. Customs management and customs clearance costs will directly affect supply chain management. Therefore, optimizing the import and export process of bonded warehousing enterprises is of great practical significance for the efficiency of import and export customs clearance, customs risks, and customs clearance costs of bonded warehousing enterprises. 


\section{Building a Data Warehouse}

The data warehouse is a database for decision analysis. First, the theme of the data warehouse is determined, which is determined by the inventory warehousing decision-making problem that decision makers are interested in. Based on this topic, the appropriate granularity and segmentation strategy are determined to build the logical structure and physical structure of the data warehouse, thus preparing for the subsequent data conversion and cleaning.

\section{Choosing a Data Mining Tool}

The storage and organization of data are completed by the data warehouse, and online analysis and processing are used for data analysis. The automatic discovery of knowledge is done by data mining. The foundation of data analysis technology is composed of data warehouse, OLAP and DM. Data warehouse can provide unified data view to data from different sources, and offer data support for data mining and OLAP. Data mining tools or OLAP tools can offer users with convenient access to information, rich data analysis and report statistics functions, so that the inventory management data of logistics enterprises can be fully utilized.

\section{Choosing Visual Tools}

The interface between user and system is performed by visual tools. On the one hand, its main work is to present the results of system response in form of image in front of users. On the other hand, the user's request is handled by the system, which requires the use of visual tools to transform the request into recognizable data. Relying on the promotion and application of data warehouse technology, the inventory decision support system has found a feasible and efficient solution. In the inventory management of logistics industry, data warehouse technology is combined with inventory decision support system based on conventional DSS function. Data warehouse technology and DM technology are used to enhance the functions of DSS (Wang., 2008). The basic formula of net present value is as follows:

$$
N P V=\sum \frac{C_{1}-C_{0}}{1+i}
$$

Combined with the actual situation of this study, the net present value formula is transformed into (Yassine., 2017):

$$
N P V=\sum Q-T_{v n}-T_{W n}-T
$$

The quantitative evaluation value is in form of an exact number, and a linear normalization function is used to standardize the quantitative evaluation value data (Chien., 2009):

$$
T=\frac{R-R_{j}^{-}}{r-r^{+}}
$$

The variable weight function of inferior matrix $\gamma$ is set as (Wang., 2017): 


$$
\gamma=\varpi_{j}^{i} s^{s(\mathrm{x}-1)}
$$

\section{RESULTS AND DISCUSSION}

PCB analysis is the analysis of storage and transportation units, which can also be called cargo status analysis. It is a kind of logistics unit that examines the items in the logistics operation. It is divided into three ways: pallet $\mathrm{P}$, box $\mathrm{C}$, and single product $\mathrm{B}$. The order quantity of the bonded warehouse is converted into the basic storage and transportation unit to analyze the goods' status. The basic storage and transportation unit of each order and each commodity item should be understood to analyze the characteristics of commodity logistics packaging, thus understanding the customer's ordering scale and the outbound scale of acquired commodities. In the warehouse logistics of bonded warehouse, the packaging status of goods will change with the requirements of different business processes in the process from warehousing to sorting out. The storage and transportation units of common bonded warehouses are shown in Table 1.

Table 1. Storage and transportation units of common bonded warehouses

\begin{tabular}{|l|l|l|l|}
\hline Numbering & Storage unit & Sorting unit & Mark \\
\hline 1 & Tray & Tray & P $\rightarrow$ P \\
\hline 2 & Tray & Box & P $\rightarrow$ C \\
\hline 3 & Box & Box & C $\rightarrow$ C \\
\hline 4 & Box & Single product & C $\rightarrow$ B \\
\hline 5 & Single product & Single product & B $\rightarrow$ B \\
\hline
\end{tabular}

Here, the commodity order data of January from MY bonded warehouse is randomly selected for basic data analysis. According to the monthly order data, the order information is converted into storage and transportation unit analysis, as shown in Figure 7. It can be seen that the number of orders in the whole pallet is very small, only $0.26 \%$, which can be delivered directly $(\mathrm{P} \rightarrow \mathrm{P})$ or by picking whole container $(\mathrm{P} \rightarrow \mathrm{C})$. Tray type automatic storage + conveyor or tray type automatic storage + discharger + sorter + conveyor is adopted for delivery. The number of orders in FCL is not very large, and the number of documents is not large. The mobile shelf + conveyor $(\mathrm{C} \rightarrow \mathrm{C})$ or mobile shelf + unpacking sorting + conveyor $(\mathrm{C} \rightarrow \mathrm{B})$ will be used for direct delivery. The number of orders based on single item is the largest, exceeding $94.35 \%$. Each detachable single category in the sorting area should be kept in stock to store the single item, and the single item picking $(\mathrm{B} \rightarrow \mathrm{B})$ mode is adopted for delivery. Through the analysis of the order storage and transportation units, three kinds of picking and delivery modes can be combined, including the whole unit, the whole container storage and the single product sorting. The facilities and equipment of automated warehouse can be used effectively, and the operation efficiency of warehouse logistics can be improved.

The EQIEN analysis is shown in Figure 8. Generally speaking, there are more varieties with larger order quantity and less varieties with smaller order quantity. For example, orders E1, E4, E8, E146-E153, E182, E183, E197, E198 and other shipments and items are large. Orders E18-E27 except E22, E62-E111 except E99 and E107, E122-E145, E189-E193 and the number of shipments are relatively small. It is obvious from the Figure 8 that this kind of orders account for the vast majority. There are also some orders with higher EN and medium EQ, such as E29-E33, E35-E38, 
Figure 7. Analysis of storage and transportation units (The histogram is $A$ to $F$ from left to right)

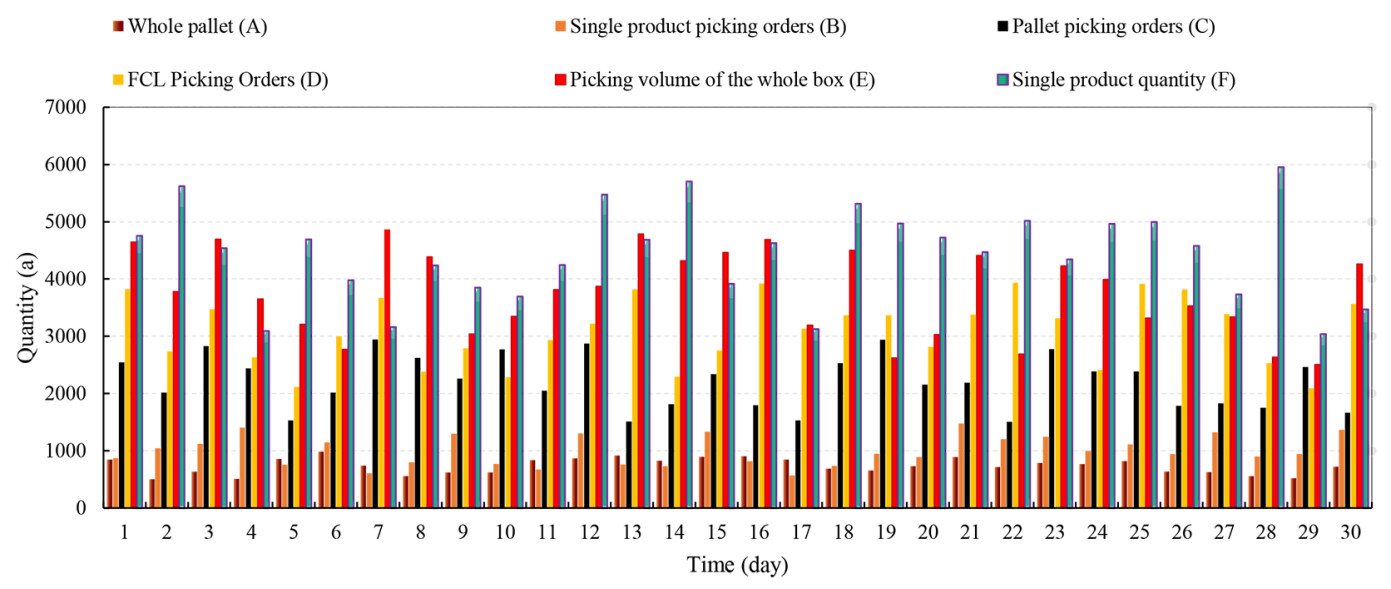

Figure 8. EQIEN analysis

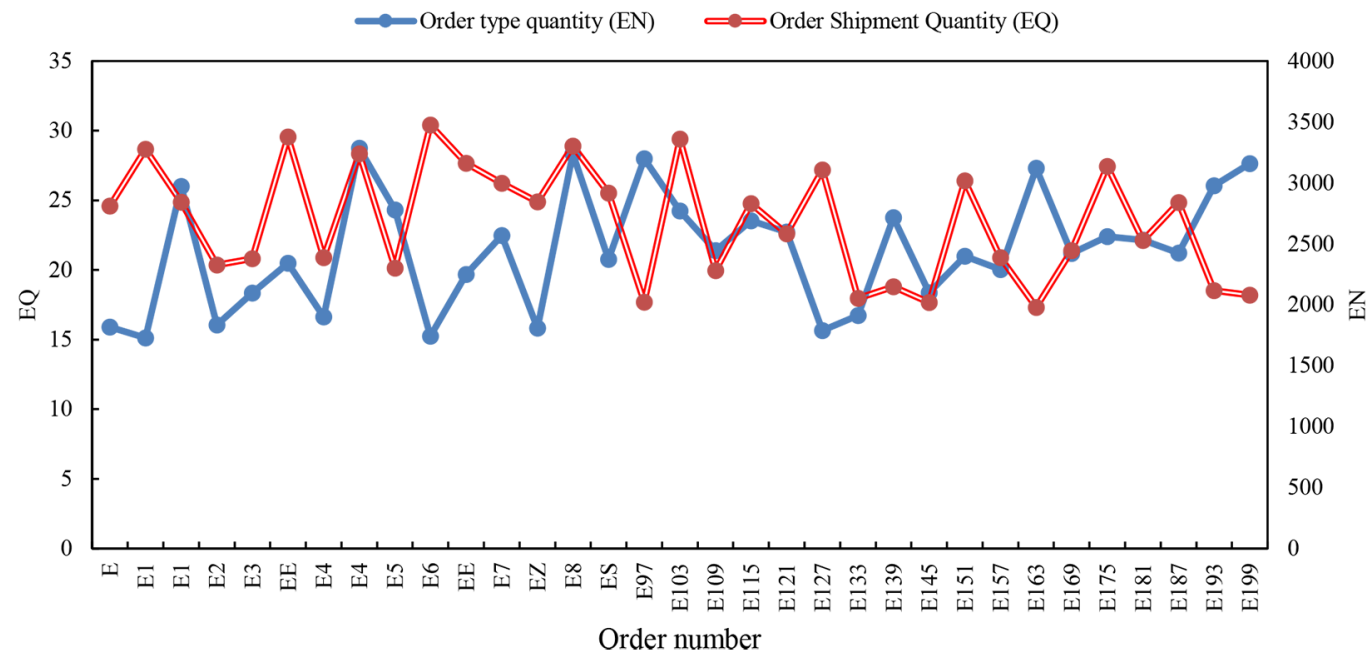

E112-E121, etc. Considering EQ and EN based on the order situation, the sorting and delivery of goods are selected based on each order. For the large quantity and large category, the whole pallet will be delivered directly. For the medium quantity, the whole container will be delivered by sorting, and the unpacked single product will be delivered by sorting for the small quantity and small category.

By analyzing IQ (single product shipments) and IK (single product shipments), it is found that the categories of some items are consistent and can be directly determined as the category in the ABC classification determined by the two kinds of analysis. Some items are inconsistent, such as I1 and I9 are classified as class A in IQ analysis and class B in IK analysis. I20 is divided into class B in IQ analysis and class A in IK analysis. For items with different classification categories, they are scored by warehouse internal management experts, and then weighted values are calculated to determine the item category. $90-100$ points (including 100 points) are A category. 80-90 points (including 90 points) are $\mathrm{B}$ category. 80 points (including 80 points) and below are $\mathrm{C}$ category, and the weights of IQ and IK are 0.6 and 0.4. Taking I9 as an example, the average score of experts in IQ analysis is 90 points, 
and that of experts in IK analysis is 87 . The weighted average value of 19 is 88.8 , which belongs to class $\mathrm{B}$ according to the scoring principle. The same calculation method is used to determine the $\mathrm{ABC}$ classification of the remaining IQ and IK items, and the final ABC classification of goods of different categories is shown in Table 2 .

Table 2. The final $A B C$ classification of goods of different categories

\begin{tabular}{|l|l|l|l|l|l|}
\hline $\begin{array}{l}\text { Shipment } \\
\text { varieties }\end{array}$ & $\begin{array}{l}\text { Outbound } \\
\text { quantity IQ }\end{array}$ & $\begin{array}{l}\text { IQ cumulative } \\
\text { percentage }\end{array}$ & IQ classification & $\begin{array}{l}\text { Number of } \\
\text { outbound IK }\end{array}$ & $\begin{array}{l}\text { IK cumulative } \\
\text { percentage }\end{array}$ \\
\hline I3 & 12440 & $21.05 \%$ & A & 111 & $8.01 \%$ \\
\hline I6 & 7629 & $33.96 \%$ & A & 99 & $15.15 \%$ \\
\hline I11 & 6498 & $44.96 \%$ & A & 37 & $21.43 \%$ \\
\hline I2 & 5449 & $54.18 \%$ & A & 32 & $37.34 \%$ \\
\hline I1 & 5412 & $63.34 \%$ & A & 59 & $48.85 \%$ \\
\hline I5 & 4727 & $71.34 \%$ & A & 60 & $33.26 \%$ \\
\hline I13 & 1785 & $79.66 \%$ & B & 62 & $80.95 \%$ \\
\hline I10 & 1688 & $85.51 \%$ & B & 62 & $63.13 \%$ \\
\hline I4 & 1534 & $88.11 \%$ & B & 55 & $72.15 \%$ \\
\hline
\end{tabular}

The warehousing business process of $M$ company was simulated through ExSpect simulation software. The company's distribution business process cycle time is 57.6 hours, and the time only refers to the time of the working day (i.e., 7 to 8 working days can be completed). The simulation variance is too large, and the simulation results show that the variance is basically close to 1 , indicating that the current process is volatile. Through the overall analysis of the entire business, it is found that the links in the key process can be changed into parallel business processes. In this way, a certain amount of working time can be saved. Simultaneously, some repetitive work in the existing process can be removed by studying process optimization strategy, thus reducing the time consumed by the whole process. The simulation results are shown in Table 3.

Table 3. Simulation results

\begin{tabular}{|l|l|l|l|}
\hline Subrun & $\mathbf{X}$ arrivals & X average & X variance \\
\hline 1 & 93 & 57.53468901 & 0.69489263 \\
\hline 2 & 89 & 58.72598723 & 0.85473124 \\
\hline 3 & 92 & 56.91472894 & 0.82379825 \\
\hline 4 & 101 & 56.76435622 & 0.78362349 \\
\hline 5 & 87 & 57.39748346 & 0.79247136 \\
\hline
\end{tabular}


After optimizing the entire warehousing business process, it takes only 19.1 hours to complete, which is nearly one-third less than the time before optimization. This result is also consistent with the previous analysis and verified analysis results of this work. The optimized business times are shown in Figure 9.

Figure 9. Each business time after optimization

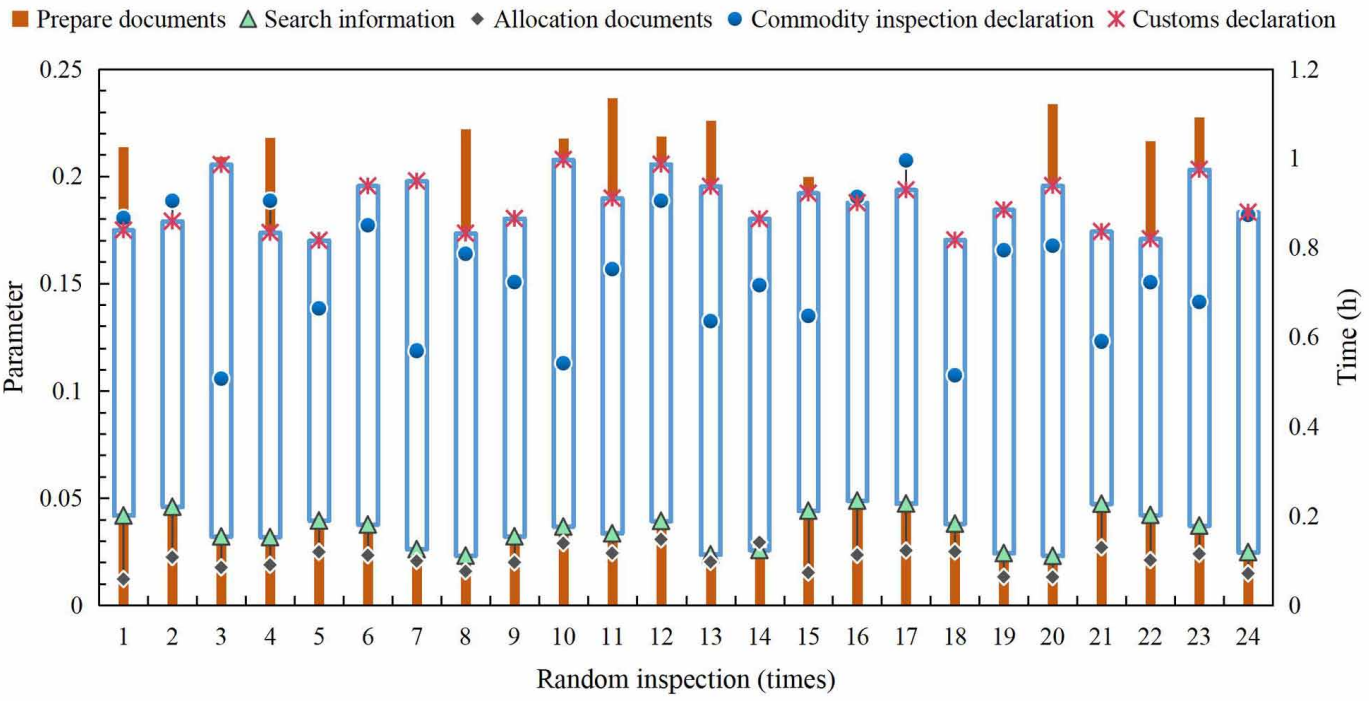

\section{CONCLUSION}

By applying the theory and method of process optimization, the mature theory was combined with the actual situation of the company. The import and export process of bonded warehouse logistics enterprises was analyzed and studied, and the past experience and lessons were summarized. The bonded warehousing logistics model which is not only in line with scientific theories but also practical import and export process was also explored, thus promoting and integrating theoretical research and practical problem solving. This work studied the development of China's logistics industry bonded warehousing decision-making for inbound and outbound goods, and presented the current problems faced by inventory warehousing in the logistics industry. The overall requirements of the logistics decision support system have been mastered. Based on the decision support system, the overall framework of the system was determined and the data warehouse was built after analyzing the technical feasibility. The decision tree algorithm in data mining technology was used to build the warehouse model of the inventory storage decision support system. At the end of this work, the visual interface of the inventory storage decision-making system is given, which has good versatility and scalability. Some links that can be optimized in the whole operation process have been found in future work, mainly including information process and customs clearance. The expected goal can be achieved by adjusting some links, improving the cooperation mode of operators, and establishing a supporting information system. On the one hand, the customs department has become increasingly standardized on related operating procedures, and it also provides great convenience for enterprises' import and export business on the other hand. For example, customs mailbox declarations are equipped with commissioners to review documents for import and export enterprises. The commissioner 
reviewing the documents can enhance customs' understanding on the enterprise's import and export products, and reduce the situation of changing and returning orders due to the lack of understanding of the enterprise's products in the customs clearance process, which will help enterprises speed up customs clearance and improve customs clearance efficiency. It can be said that the import and export departments of enterprises are facing increasing challenges and pressures.

\section{FUNDING INFORMATION}

This research received no specific grant from any funding agency in the public, commercial, or notfor-profit sectors.

\section{CONFLICT OF INTEREST}

The authors have declared to have no competing interests. 


\section{REFERENCES}

Atimu, L. K. D., \& Luo, W. (2021). Assessing domestic and regional factors influencing ghana's export trade in Africa. Open Journal of Business and Management, 9(1), 103-113. doi:10.4236/ojbm.2021.91006

Buczak, A. L., \& Guven, E. (2016). A survey of data mining and machine learning methods for cyber security intrusion detection. IEEE Communications Surveys and Tutorials, 18(2), 1153-1176. doi:10.1109/ COMST.2015.2494502

Chaurasia, V., \& Pal, S. (2017). A novel approach for breast cancer detection using data mining techniques. International Journal of Innovative Research in Computer and Communication Engineering, 2.

Chien, C. F., Huang, Y. C., \& Hu, C. H. (2009). A hybrid approach of data mining and genetic algorithms for rehabilitation scheduling. International Journal of Manufacturing Technology and Management, 16(1-2), 76-100. doi:10.1504/IJMTM.2009.021505

Constantine, P. G., \& Doostan, A. (2017). Time-dependent global sensitivity analysis with active subspaces for a lithium ion battery model. Statistical Analysis and Data Mining: The ASA Data Science Journal, 10(5), 243-262. doi:10.1002/sam.11347

Dar, Q., Dar, G. F., Ma, J. H., \& Ahn, Y. H. (2020). Visualization, Economic Complexity Index, and Forecasting of South Korea International Trade Profile: A Time Series Approach. Journal of Korea Trade, 24(1), 131-145. doi:10.35611/jkt.2020.24.1.131

Emoto, T., Yamashita, T., Kobayashi, T., Sasaki, N., Hirota, Y., Hayashi, T., So, A., Kasahara, K., Yodoi, K., Matsumoto, T., Mizoguchi, T., Ogawa, W., \& Hirata, K. I. (2017). Characterization of gut microbiota profiles in coronary artery disease patients using data mining analysis of terminal restriction fragment length polymorphism: Gut microbiota could be a diagnostic marker of coronary artery disease. Heart and Vessels, 32(1), 39-46. doi:10.1007/s00380-016-0841-y PMID:27125213

Fu, H., Li, H., \& Wang, X. (2020). The Problem of Export Trade and Countermeasures in Henan Province. World Scientific Research Journal, 6(5), 112-122.

Fu, H., \& Wang, S. (2020). Analysis of Xinyang Tea Export Trade Problems and Countermeasures. World Scientific Research Journal, 6(5), 208-216.

Helma, C., Cramer, T., Kramer, S., \& De Raedt, L. (2004). Data mining and machine learning techniques for the identification of mutagenicity inducing substructures and structure activity relationships of noncongeneric compounds. Journal of Chemical Information and Computer Sciences, 44(4), 1402-1411. doi:10.1021/ci034254q PMID:15272848

Hong, H., Tsangaratos, P., Ilia, I., Liu, J., Zhu, A. X., \& Chen, W. (2018). Application of fuzzy weight of evidence and data mining techniques in construction of flood susceptibility map of Poyang County, China. The Science of the Total Environment, 625, 575-588. doi:10.1016/j.scitotenv.2017.12.256 PMID:29291572

Lin, L., Wang, Q., \& Sadek, A. W. (2014). Data mining and complex network algorithms for traffic accident analysis. Transportation Research Record: Journal of the Transportation Research Board, 2460(1), $128-136$. doi:10.3141/2460-14

Moustakas \& Aristides. (2017). Spatio-temporal data mining in ecological and veterinary epidemiology. Stochastic Environmental Research \& Risk Assessment, 31(4), 1-6. 10.1007/s00477-016-1374-8

Ramírez-Gallego, S., Krawczyk, B., García, S., Woźniak, M., \& Herrera, F. (2017). A survey on data preprocessing for data stream mining: Current status and future directions. Neurocomputing, 239, 39-57. doi:10.1016/j. neucom.2017.01.078

Shokoohi-Yekta, M., Hu, B., Jin, H., Wang, J., \& Keogh, E. (2017). Generalizing DTW to the multi-dimensional case requires an adaptive approach. Data Mining and Knowledge Discovery, 31(1), 1-31. doi:10.1007/s10618016-0455-0 PMID:29104448

Sikos, T. T., \& Meirmanova, A. (2020). Geo-based visual network analysis of export and import patterns in international wheat trade. Geography Teacher, 15(2), 84-92. doi:10.21163/GT_2020.152.09 
To Pc Uolu, A., \& Oral, I. O. (2020). Mst lkelerinde d ticaret likileri ve thalata bamllk analizi - foreign trade relations and import dependency analysis in mist countries. Turkish Studies - Economics Finance Politics, 15(2), 941-958. 10.29228/TurkishStudies.39787

Triguero, I., González, S., Moyano, J. M., García, S., Alcalá-Fdez, J., Luengo, J., Fernández, A., del Jesús, M. J., Sánchez, L., \& Herrera, F. (2017). KEEL 3.0: An open source software for multi-stage analysis in data mining. International Journal of Computational Intelligence Systems., 10(1), 1238-1249. doi:10.2991/ijcis.10.1.82

Varley, J. B., Miglio, A., Ha, V. A., van Setten, M. J., Rignanese, G. M., \& Hautier, G. (2017). High-throughput design of non-oxide p-type transparent conducting materials: Data mining, search strategy, and identification of boron phosphide. Chemistry of Materials, 29(6), 2568-2573. doi:10.1021/acs.chemmater.6b04663

Wang, B., Chen, D., Shi, B., Zhang, J., Duan, Y., Chen, J., \& Hu, R. (2017). Comprehensive association rules mining of health examination data with an extended FP-growth method. Mobile Networks and Applications, 22(2), 267-274. doi:10.1007/s11036-016-0793-6

Wang, J., Hu, X., Hollister, K., \& Zhu, D. (2008). A comparison and scenario analysis of leading data mining software. International Journal of Knowledge Management, 4(2), 17-34. doi:10.4018/jkm.2008040102

Wang, P., Chen, T., \& Wang, Z. (2019). Research on privacy preserving data mining. Journal of Information Hiding and Privacy Protection, 1(2), 61-68. doi:10.32604/jihpp.2019.05943

Xu, L., Jiang, C., Wang, J., Yuan, J., \& Ren, Y. (2014). Information security in big data: Privacy and data mining. IEEE Access: Practical Innovations, Open Solutions, 2, 1149-1176. doi:10.1109/ACCESS.2014.2362522

Yan, X. S., \& Zheng, L. (2017). Fundamental analysis and the cross-section of stock returns: A data-mining approach. Review of Financial Studies, 30(4), 1382-1423. doi:10.1093/rfs/hhx001

Yassine, A., Singh, S., \& Alamri, A. (2017). Mining human activity patterns from smart home big data for health care applications. IEEE Access: Practical Innovations, Open Solutions, 5, 13131-13141. doi:10.1109/ ACCESS.2017.2719921

Yensu, E. (2019). Export, import and economic growth relationship in turkey: Ardl bound testing approach. Gaziantep University Journal of Social Sciences, 18(3), 1175-1193. doi:10.21547/jss.418935

Yücer, A., \& Siroën, J. M. (2017). Trade performance of export processing zones. World Economy, 40(5), 1012-1038. doi:10.1111/twec. 12395

Yanan Song received her PhD in Applied Economics from Xi'an Jiaotong University in 2008. In 2009 she was hired as Assistant Professor by School of Business at Macau University of Science and Technology and is currently the Associate Professor and Coordinator of international Trade major of School of Business at Macau University of Science and Technology. She writes and presents widely on international trade and investment issues, big data analytics in trade and investment. And she also actively conducted and published a series of projects and books on business investments of Lusophone countries and Sino-Lusophone counrties' business cooperation.

Xiaolong Hua received his Ph. D. in Applied Economics from Xi'an Jiaotong University in 2009. In 2009 he was hired as the Lecturer by the School of Finance at Inner Mongolia University of Finance and Economics, and now he is a Professor. He wrote and presented on issues of energy product pricing and big data analysis, and published more than 20 papers in journals such as The Journal of Quantitative and Technical Economics, Economic Management, Humanities Journal and Economic Research Reference, etc. 